\title{
In Situ Synthesis of $\mathrm{TiB}_{2} / \mathrm{NiAl}$ Composite
}

\author{
Heng ZHANG ${ }^{1, a}$, He-Guo ZHU ${ }^{1,2, b,{ }^{*}}$ \\ ${ }^{1}$ College of Materials Science and Engineering, Nanjing University of Science and Technology, \\ Nanjing, 210094; P. R. China \\ ${ }^{2}$ Key Laboratory of Jiangsu Province Higher Education Institutions on Advanced Micro-Nano \\ Materials and Technology \\ a951561042@qq.com, b'zhg1200@sina.com \\ ${ }^{*}$ Corresponding author
}

Keywords: In Situ Synthesis Technology, NiAl Matrix Composites, Thermodynamics.

\begin{abstract}
In situ synthesis technology was used to synthesize the NiAl matrix composite reinforced by $\mathrm{TiB}_{2}$ which were fabricated by induction heating furnace in this work. Modern testing technologies were applied to analyze the microstructures of the products and the reaction process. The results showed that the composite consisted of $\mathrm{NiAl}$ and $\mathrm{TiB}_{2}$ phases. The ignition temperatures of $\mathrm{Ni}+\mathrm{Al} \rightarrow \mathrm{NiAl}$ and $\mathrm{Ti}+2 \mathrm{~B} \rightarrow \mathrm{TiB}_{2}$ were approximately $626^{\circ} \mathrm{C}$ and $1029^{\circ} \mathrm{C}$ when heating in $20 \mathrm{~K} / \mathrm{min}$. The activation energy of above reactions were $295.86 \mathrm{~kJ} / \mathrm{mol}$ and $113.08 \mathrm{~kJ} / \mathrm{mol}$, respectively. $\mathrm{TiB}_{2}$ phase with fine particle was uniformly distributed in the $\mathrm{NiAl}$ matrix in the form of hexagonal prism.
\end{abstract}

\section{Introduction}

$\mathrm{NiAl}$ inter-metallic compounds are a new type of high-temperature structural materials which possess high melting point, low density, high thermal conductivity and excellent oxidation resistance along with some other characteristics, therefore, they are widely used in the aerospace and military industry ${ }^{[1,2]}$.

In situ synthesis is a new method for preparing composite materials which have recently developed. The basic principle is to rely on alloy composition design. Using in situ synthesis in different elements or substances, chemical reactions will take place, and in the metal matrix, it can generate one, even several kinds of high hardness, and high elastic modulus of ceramic or inter-metallic compound as the reinforcing phase to improve the performance of a single metal alloy. The enhanced phase thermodynamically driven by in situ reaction is stable, the distribution is relatively uniform; the reinforced phase and matrix of the coherent is good, the interface with high bonding strength is clear. So compared with matrix metal, composite material has better mechanical properties at both room and high temperature. In this experiment, we use the thermal explosion reaction technology to in situ synthesize the NiAl matrix composite from Ni-Al-Ti-B system, explore the process and product of the composite materials, thus, provide a new direction for the preparation of the NiAl inter-metallic compounds ${ }^{[3-7]}$.

\section{Experiment Procedures}

Raw materials of this experiment were titanium powder $(3-5 \mu \mathrm{m}, 99 \%$ purity), aluminum powder (3-50 $\mu \mathrm{m}, 99 \%$ purity), nickel powder $(10 \sim 30 \mu \mathrm{m}, 99.8 \%$ purity) and boron powder $(3-10 \mu \mathrm{m}, 99 \%$ purity). Produce NiAl-based composites with reinforcement volume fraction of $20 \%$ (i.e. $20 \mathrm{vol}$. $\%$ $\mathrm{TiB} 2+80$ vol. $\% \mathrm{NiAl}$ ), the powder mixture of $\mathrm{Al}, \mathrm{Ti}, \mathrm{B}$ and $\mathrm{Ni}$ were prepared with their respective volume fractions derived from the reaction equation $\mathrm{Ti}+2 \mathrm{~B}+\mathrm{Ni}+\mathrm{Al} \rightarrow \mathrm{TiB}_{2}+\mathrm{NiAl}$. The weight ratio of $\mathrm{Al}, \mathrm{Ti}, \mathrm{B}$ and $\mathrm{Ni}$ in the mixed powder is thus $17.55 \% ; 16.96 \% ; 7.64 \% ; 57.85 \%$ (in wt. \%). The powder mix was first ball-milled in a stainless steel vacuum jar for $4 \mathrm{~h}$ and then compacted under a pressure of $180 \mathrm{MPa}$ into cylindrical specimens with a diameter of $20 \mathrm{~mm}$ and height about $5 \mathrm{~mm}$. The cylindrical specimens were first placed in a vacuum jar and an induction heating furnace. The 
temperature of the compact was measured by a thermal couple and plotted as a function of heating time. After reaction, the furnace was turned off and cooled down to room temperature. And the composite samples were mechanically polished and investigated by using X-ray diffraction (XRD, RigakuD/MAX2400), and scanning electron microscopy (SEM, Quanta 2000). In order to obtain the differential scanning calorimetry (DSC, Netzsch STA449C) curves, the compact samples were heated in argon atmosphere in the furnace of STA449C thermal analyzer, wherein the temperature was increased from the ambient $\left(20^{\circ} \mathrm{C}\right)$ to $1150^{\circ} \mathrm{C}$ at different heating rate such as $10 \mathrm{k} / \mathrm{min}$; $15 \mathrm{k} / \mathrm{min} ; 20 \mathrm{k} / \mathrm{min} ; 25 \mathrm{k} / \mathrm{min}$. The reactions occurring in the Ni-Al-Ti-B system during the heating process were analyzed.

\section{Results and Discussion}

\section{Thermodynamics Calculation}

According to common Gibbs-Heimalmholtz approximate calculation equation ${ }^{[8]}$ :

$$
\Delta G_{T}^{\theta}=\Delta H_{298}^{\theta}-T \Delta S_{298}^{\theta}
$$

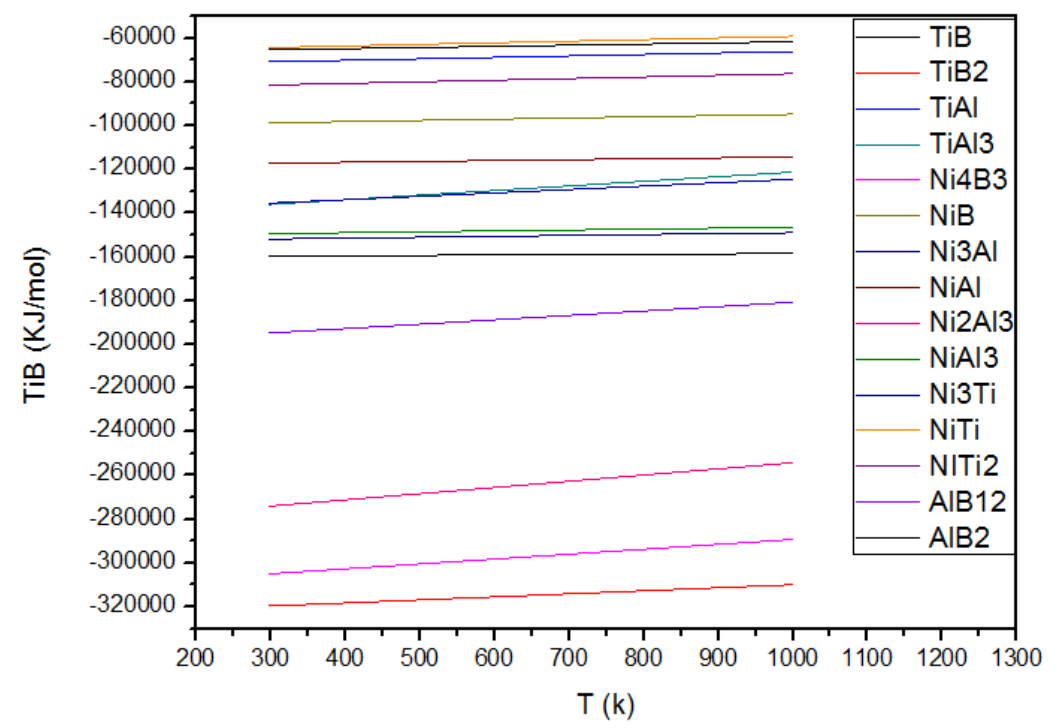

Fig.1 Curves of Free Energy

Figure 1 showed the Gibbs function relation expression of the 15 products which may exist in the reaction referring to the practical inorganic thermodynamics data. Based on the figure 1 all the values of the function relations were negative meaning that the reactions can take place spontaneously in terms of thermodynamics.

\section{DSC Analysis}

Figure 2 showed the DSC curves of different system and different heating rates. Figure 2 (a) showed the DSC superposition curve of Ni-Al, Ni-B, Ni-Ti, Ti-B, Ti-Al and Al-B; (b) showed the DSC curve of Ni-Al-Ti-B; (c) showed the DSC curve of different heating rates. From Figure 2 (a), it can be concluded that the reaction sequence of four elements $\mathrm{Ni}, \mathrm{Al}, \mathrm{Ti}, \mathrm{B}$ as follow: $\mathrm{Al}$ and $\mathrm{B}$ reacted at $659^{\circ} \mathrm{C}, \mathrm{Ni}$ and $\mathrm{Al}$ at $550^{\circ} \mathrm{C}, \mathrm{Ni}$ and $\mathrm{B}$ at $588^{\circ} \mathrm{C}$, Ti and $\mathrm{Al}$ at $665^{\circ} \mathrm{C}$. Ti and $\mathrm{B}$ at $1080^{\circ} \mathrm{C}$, $\mathrm{Ni}$ and $\mathrm{Ti}$ at $1109^{\circ} \mathrm{C}$. According to the curve of Gibbs free energy (Figure 1), the reaction $\mathrm{Ti}+2 \mathrm{~B} \rightarrow \mathrm{TiB}_{2}$ has the minimum free energy function value meaning it was the most likely reaction in each of the six reactions. Meanwhile, it corresponded to the second exothermic peak $\left(1080^{\circ} \mathrm{C}\right)$ in Figure 2 (b). The reaction of $\mathrm{Ni}-\mathrm{Al}$ corresponded to the first exothermic peak $\left(633^{\circ} \mathrm{C}\right)$ in Figure 2 (b). From figure 2 (c), it showed the DSC curves with heating rate of $10 \mathrm{~K} / \mathrm{min}, 15 \mathrm{~K} / \mathrm{min}$, 
$20 \mathrm{~K} / \mathrm{min}$ and $25 \mathrm{~K} / \mathrm{min}$. Peak A represented the reaction: $\mathrm{Ni}+\mathrm{Al} \rightarrow \mathrm{NiAl}$ and peak $\mathrm{B}$ represented the reaction: $\mathrm{Ti}+2 \mathrm{~B} \rightarrow \mathrm{TiB}_{2}$. Four different heating rates of $\mathrm{DSC}$ curves emerged exothermic peak $\mathrm{A}$ between $633^{\circ} \mathrm{C}$ and $635^{\circ} \mathrm{C}$. While the exothermic peak $\mathrm{B}$ appeared at a temperature ranging from $1023^{\circ} \mathrm{C}$ to $1080^{\circ} \mathrm{C}$. The law is that the endothermic peak will move to the high temperature zone if the heating rate was raised.

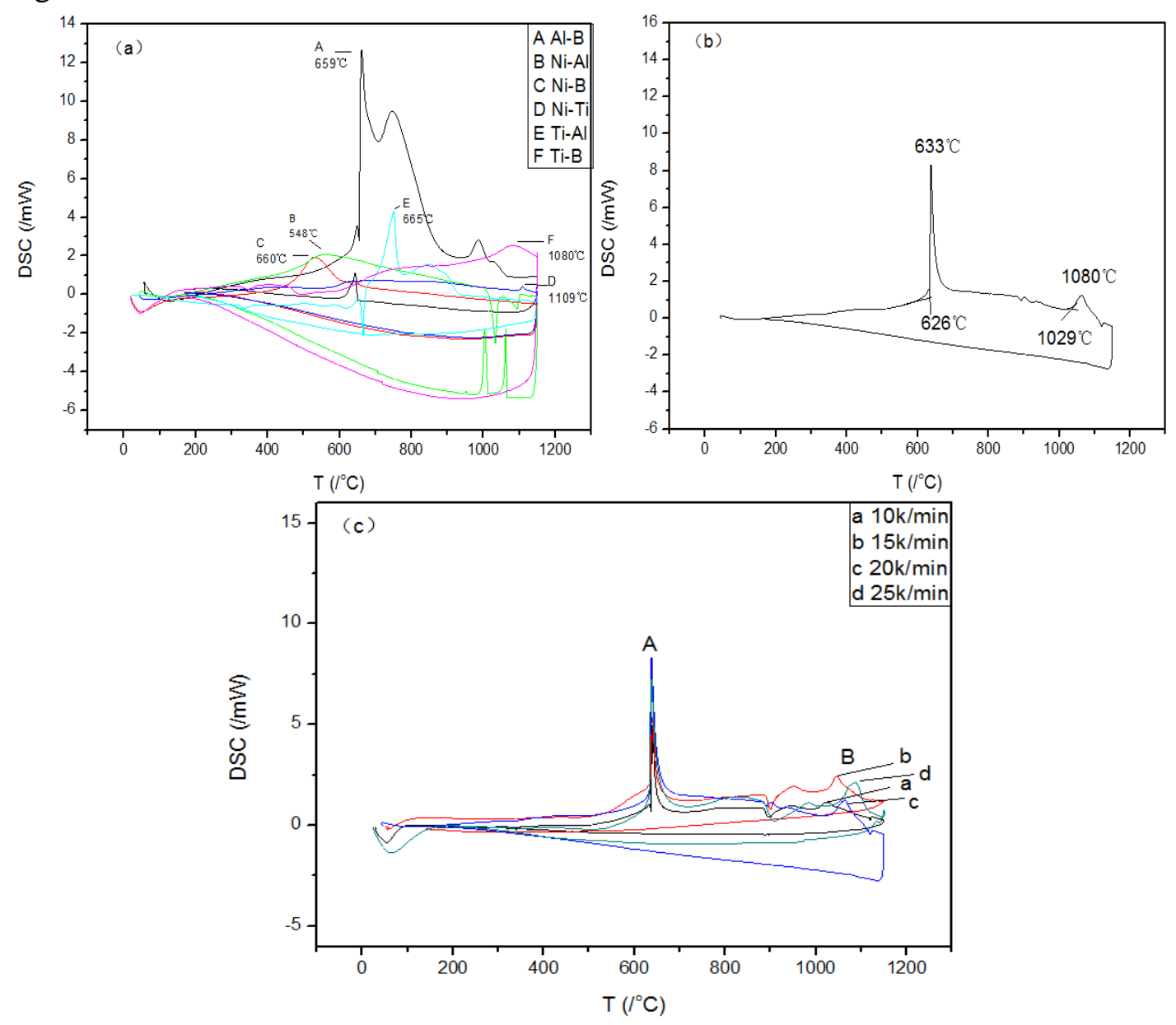

Fig.2 (a) DSC Superposition Curves of Ni-Al, Ni-B, Ni-Ti, Ti-B, Ti-Al, Al-B (b) DSC Curve of Ni-Al-Ti-B (c) DSC Curves of Different Heating Rates of 10K/min, 15K/min, 20K/min and $25 \mathrm{~K} / \mathrm{min}$

According to the Kissinger equation ${ }^{[9]}$ :

$$
-E / R=\frac{\mathrm{d} \ln \frac{\beta}{\mathrm{T}_{\mathrm{m}}^{2}}}{\mathrm{~d} \frac{1}{\mathrm{~T}_{\mathrm{m}}}}
$$

Figure 3 showed the regression curves of reaction A and reaction B (Figure 2 (c)). The activation energy can be calculated using the equation above. As it was shown in Figure 3 the slope of the regression line was the activation energy. According to Figure 3 (a) and (b), the activation energy of reaction A can be calculated: $E_{(\mathrm{A})}=295.86 \mathrm{~kJ} / \mathrm{mol}$. The activation energy of reaction B: $E_{(\mathrm{B})}=113.08 \mathrm{~kJ} / \mathrm{mol}$. 

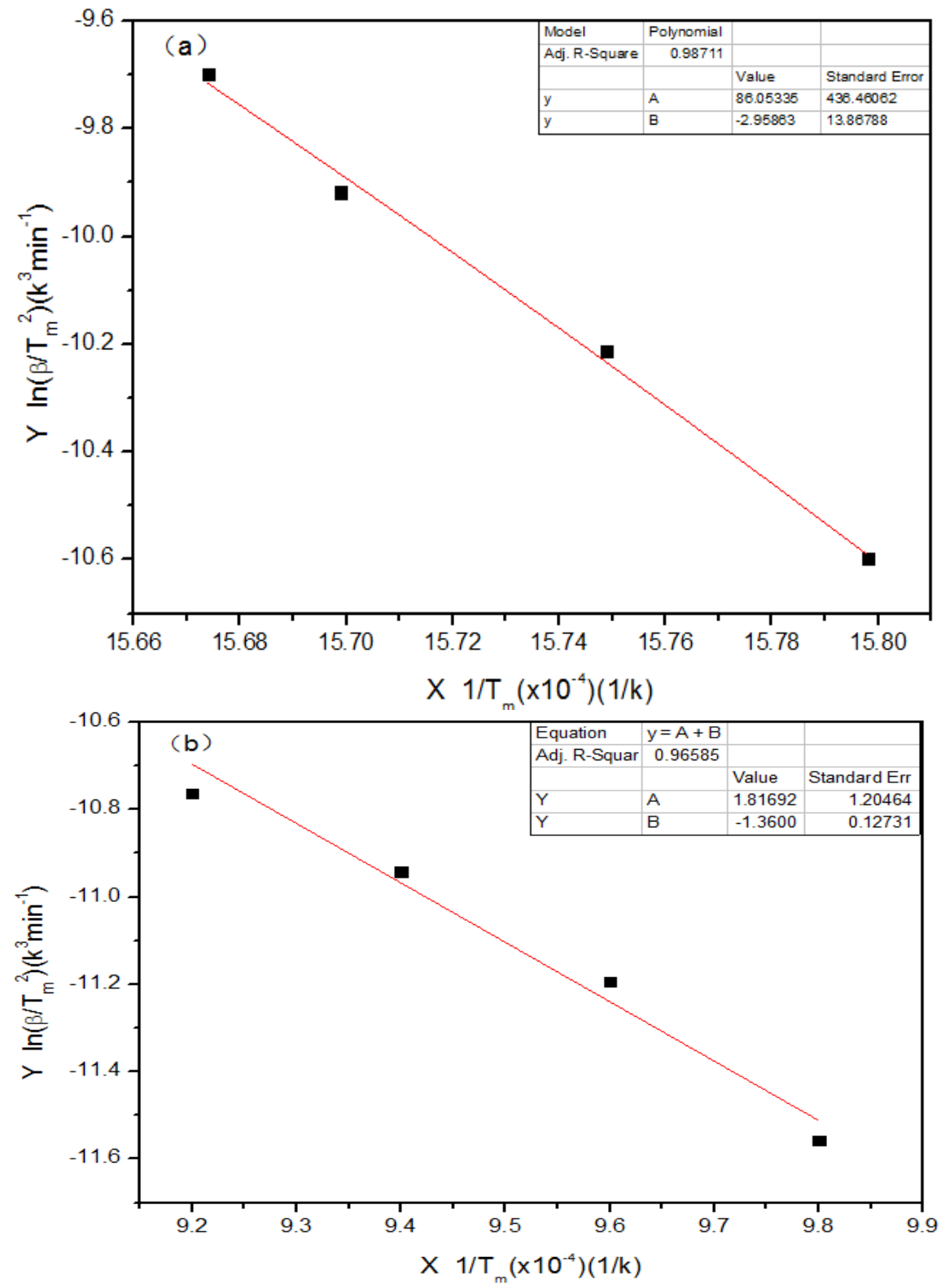

Fig.3 (a) The Regression Curve of Point A (b) The Regression Curve of Point B

\section{X-Ray Diffraction and Morphology Analysis}

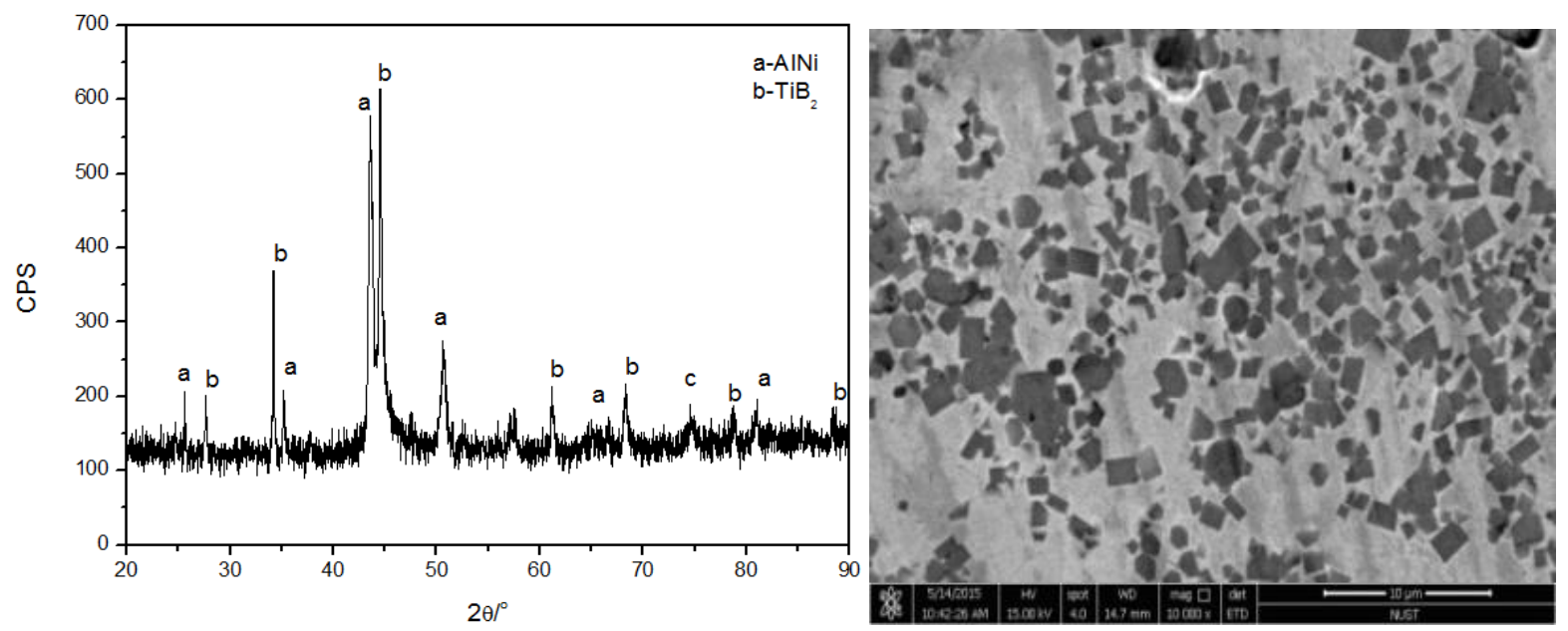

Fig.4 Diffraction Diagram of the Sample Fig.5 SEM Photograph of the Sample 
Figure 4 showed the diffraction diagram of the composite and figure 5 was the SEM photograph of the composite. It can be seen from Figure 4, that the sample was mainly $\mathrm{NiAl}$ and $\mathrm{TiB}_{2}$ phases. The matrix of this composite was $\mathrm{NiAl}$ and $\mathrm{TiB}_{2}$ was the reinforcement.

In the SEM photograph (Figure 5) the rectangle and hexagon area was the $\mathrm{TiB}_{2}$ phase surrounded by the matrix constituent by $\mathrm{NiAl}$ phase. The $\mathrm{TiB}_{2}$ phases with fine particles were distributed uniformly in the matrix in the form of hexagonal prism through the photograph.

\section{Summary}

(1) The composite was constituent by matrix $\mathrm{NiAl}$ and reinforcement $\mathrm{TiB}_{2}$. The fine particle $\mathrm{TiB}_{2}$ in the form of hexagonal prism was distributed uniformly in the matrix.

(2) The ignition temperature of $\mathrm{Ni}+\mathrm{Al} \rightarrow \mathrm{NiAl}$ and $\mathrm{Ti}+2 \mathrm{~B} \rightarrow \mathrm{TiB}_{2}$ were $626^{\circ} \mathrm{C}$ and $1029^{\circ} \mathrm{C}$. The activation energy of the above reactions were $295.86 \mathrm{~kJ} / \mathrm{mol}$ and $113.08 \mathrm{~kJ} / \mathrm{mol}$.

\section{Acknowledgement}

This work was supported by the National Natural Science Foundations of China (No. 51371098 and No.51571118) and Natural Science Foundations of Jiangsu Province, China (grant no. BK20141308).

\section{References}

[1] J. Shi, Z.H. Cao, M.Z. Wei, G.J. Pan, L.J. Xu, X.K. Meng, Multiple effects of Ni-rich precipitates in Ni-Ti-Al thin films, Materials Science \& Engineering A. 623 (2015):104-108.

[2] Y.B. Yuan, Z.W. Wang. Effect of mechanical alloying and sintering process on microstructure andechanical properties of $\mathrm{Al}-\mathrm{Ni}-\mathrm{Y}-\mathrm{Co}-\mathrm{La}$ alloy. Trans. Nonferrous Met. Soc. 24 (2014): 2251-2257.

[3] H.G. Zhu, K. Dong, J.W. Huang, J.L. Li, G. Wang, Z.H. Xie, Reaction mechanism and mechanical properties of an aluminum-based composite fabricated in-situ from $\mathrm{Al}_{-} \mathrm{SiO}_{2}$ system, Materials Chemistry and Physics. 145 (2014): 334-341.

[4] H.G. Zhu, Y.L. Ai, J.L. Li, J. Min, D.Chu, J. Zhao, J. Chen, In situ fabrication of $\alpha-\mathrm{Al} 2 \mathrm{O} 3$ and Ni2Al3 reinforced aluminum matrix composites in an Al-Ni2O3 system, Advanced Powder Technology. 22(2011): 629-633.

[5] H.G. Zhu, G.H. Guo, T. Cui, J.W. Huang, J.L. Li, Z.H. Xie, In situ aluminum matrix composites fabricated from Al-Ni2O3system through microwave synthesis, Materials Chemistry and Physics. 153(2015): 333-337.

[6] V. Udhayabanu, K.R. Ravi, B.S. Murty,Development of in situ NiAl-Al2O3 nanocomposite by reactive milling and spark plasma sintering, Journal of Alloys and Compounds. 509(2011): 223-228.

[7] S. Schlabach, D.V. Szabo, D. Vollath, P.de laPresa, M.Forker, Zireonia and titania nano Partieles studied by electric hyperfine interaetions, XRD and TEM. Joumal of Alloys and Compounds. 31(2007):50-59.

[8] D.L. Ye, J.H. Hu. Practical inorganic thermodynamic data manual. Metallurgical Industry press, Beijing, 2002.

[9] H.G. Zhu, K. Dong, H. Wang, J.W. Huang, J.L. Li, Z.H. Xie, Reaction mechanisms of the TiC/Fe composite fabricated by exothermic dispersion from $\mathrm{Fe}-\mathrm{Ti}-\mathrm{C}$ element system, Powder Technology. 246 (2013):456-461. 